A 3-year old girl suffering from acute lymphoblastic leukemia (pre-B immunophenotype, medium risk, treatment protocol ALL IC-BFM 2009) during maintenance therapy (MTX 10mg/ weekly/and 6-mercaptopurine 50mgm2 daily) had sudden onset of pallor, oliguria, and microhematuria $(128 \mathrm{RBC} / \mathrm{mm} 3)$. Initial complete blood count revealed normocytic anemia ( $\mathrm{Hb}$ $59 \mathrm{~g} / \mathrm{L}$, Htc 16.3\%, MCV 85.3 fL, platelets 26 x109/L) alongside elevated bilirubin $(67 \mathrm{umol} / \mathrm{L})$, urea $(17.6 \mathrm{umol} / \mathrm{L})$, creatinine $(82 \mathrm{umol} / \mathrm{L})$ and $\mathrm{LDH}(2296 \mathrm{U} / \mathrm{L})$ and a reduced haptoglobin level $(0.03 \mathrm{~g} / \mathrm{L})$. Plasma-free hemoglobin was elevated $(154 \mathrm{mg} / \mathrm{L})$, as well as d-dimers $(2.87 \mathrm{mg} / \mathrm{L})$, antithrombin III (126.8\%), and fibrinogen(6 g/L). Immunohematological analysis (direct and indirect Coombs test, antiplatelet antibodies) was negative.

Hematological data: $\mathrm{Hb}$ level $(45 \mathrm{~g} / \mathrm{L})$, minimum platelets count $(3 \times 109 / \mathrm{L})$, maximum LDH level units $(704.8 \mathrm{U} / \mathrm{L})$, schistocytes seen (no). Renal impairment: oliguria with macrohematuria, maximum serum creatinine $(86 \mu \mathrm{mol} / \mathrm{L})$, creatinine clearance (Schwartz formula) $23 \mathrm{ml} / \mathrm{min} / 1.73 \mathrm{~m} 2$. Evidence of infective causes: no (stools O157:H7, Shigella sp, VTEC, Streptococcus pneumoniae). Endomysial antibodies (EMA), ANCA, methylmalonic aciduria, hyperhomocysteinemia negative. Renal histology: not done Laboratory investigation: reduced ADAMS-13 activity (40\%, reference range 67-150\%) with normal C3 $(0.75 \mathrm{~g} / \mathrm{L}), \mathrm{C} 4(0.27 \mathrm{~g} / \mathrm{L})$. Factor H level was high (1248 mg/L, reference range $250-880 \mathrm{mg} / \mathrm{L})$ with terminal pathway activation marker level markedly increased (1315 $\mathrm{ng} / \mathrm{mL}$, ref. range $110-252 \mathrm{ng} / \mathrm{mL}$ ), supporting pathological overactivation of the complement system.

Treatment: The girl was initially treated with fresh frozen plasma, periodic RBC transfusions, and single plasmapheresis. On the 2 nd day of admission, she received a first eculizumab infusion $(300 \mathrm{mg})$. After application, we noticed an immediate increase in platelets and reticulocytes with a decrease in free plasma hemoglobin and global renal function recovery. Moderate hypertension that occurred was treated with enalapril and amlodipine. The former maintenance therapy was immediately switched to cyclophosphamide. The girl is well, with continued eculizumab treatment on a recommended schedule.

Genetic analysis: The patient was found to be homozygous for the $\mathrm{CFH} \mathrm{H} 3$ haplotype (involving the rare alleles of c.331C>T, Q672Q, and E936D polymorphisms) reported as a risk factor of aHUS. The patient was homozygous for the MCPggaac haplotype of the CD46 gene reported as a risk factor of developing aHUS.

Conclusion A triggering factor for thrombotic microangiopathy was drug-mediated, causing complement activation on a predisposing genetic background. To our best knowledge, this is the third similar case found in literature, the first to receive eculizumab in such cases as well as following early onset of complement activation disease.

\section{AUTOIMMUNE HEMOLYTIC ANEMIA WITH COMPLEMENT ACTIVATION MIMICKING AHUS}

Dejanovic-Bekic Sara*, Mucavac Lucija, Turudic Daniel, Pavlovic Maja, Milosevic Danko, Bilic Ernest. University Hospital Centre Zagreb

\subsection{6/archdischild-2021-europaediatrics.311}

A boy of 5 years was admitted into the Division for Pediatric Hematology and Oncology due to severe anemia. Initial complete blood count showed severe macrocytic anemia (Hb $44 \mathrm{~g}$ /
L, Htc 14.9\%, MCV 112.6 fL), elevated Rtc count (34.7\%, $158.7 / 1000$ erythrocytes), and slightly reduced platelet count (110 x109). The boy had hemolysis (low haptoglobin level $(<0.10 \mathrm{~g} / \mathrm{L})$, elevated bilirubin, and $\mathrm{LDH}$, with complement activation (C4 $0.72 \mathrm{~g} / \mathrm{L}, \mathrm{C} 30.02 \mathrm{~g} / \mathrm{L}, \mathrm{CH} 50$ 13\%). Urea (3.3 $\mathrm{mmol} / \mathrm{L})$ and creatinine $(19 \mathrm{umol} / \mathrm{L})$ were within reference values. Exclusion diagnostics: malignant hematological disorders (bone marrow biopsy), folate deficiency anemia, and vitamin B12 deficiency. Immunohematological analysis: autoimmune hemolytic anemia with positive both direct and indirect antiglobulin (Coombs) test.

The erythrocytes were coated with warm IgG autoantibodies and $\operatorname{IgM}$ class autoantibodies in a wide temperature range $\left(4-37^{\circ} \mathrm{C}\right)$ without erythrocyte specificity alongside activated complement components while the platelets were coated with IgM autoantibodies. ADAMTS13 activity was decreased (38\%), but not deficient alongside low $\mathrm{C} 1 \mathrm{q}$ antigen, low Factor $\mathrm{H}$ antigen $(84 \mathrm{mg} / \mathrm{L}$, ref. range $250-880 \mathrm{mg} / \mathrm{L}$ ) and low sC5b-9 (terminal complement complex) $(301 \mathrm{ng} / \mathrm{mL}$, ref. range 110 $252 \mathrm{ng} / \mathrm{mL}$ ) Treatment: intravenous methylprednisolone $(6 \mathrm{mg} /$ $\mathrm{kgBW} / 14$ consecutive days) with periodical erythrocyte and platelet concentrate transfusions, rituximab once weekly (5 doses in total); plasmapheresis (6 cycles in total, with side effects which included increased tendency clotting). These therapeutic strategies showed no therapeutic benefit, and the child was dependant on periodic RBC and platelet transfusions. The therapy was switched to IVIg $(4,7 \mathrm{~g} / \mathrm{kg} / 5$ days) and vitamin B12 (1000 mcg/daily/7 days), with significant improvement of RBC and platelet count.

Genetic analysis: a heterozygous mutation for a rare intronic variation (c.600-14C>T) and heterozygous for the $\mathrm{Y} 402 \mathrm{H}$ polymorphism of the $\mathrm{CFH}$ gene.

c.600-14C $>\mathrm{T}$ mutation is located near the 5' end of exon 6 in the gene encoding the complement $\mathrm{C} 3$ protein (C3). This rare variation was described previously in one patient with aHUS, in one patient with glomerulonephritis, in one subject suffering from C3-deficiency, and one patient with agerelated macular degeneration. This rare variation was also identified in healthy subjects with a relatively low frequency (0.04-1.1\%), but no functional studies were performed on its possible role.

Conclusion We believe that the underlying disease was autoimmune hemolytic anemia with both cold and warm autoantibodies complicated with complement activation on predisposing genetic background.

\section{HEALTH-RELATED QUALITY OF LIFE IN INFANTS, TODDLERS AND YOUNG CHILDREN WITH SICKLE CELL DISEASE}

ME Houwing, MJ Muntendam*, MM van Muilekom, L Teela, K Fijnvandraat, PJA de Pagter, HA van Oers, MH Cnossen, L Haverman. Erasmus University Medical Center - Sophia Children's Hospital, Rotterdam, The Netherlands

\subsection{6/archdischild-2021-europaediatrics.312}

Little is known about health-related quality of life in children with sickle cell disease aged 0-7 years old living in an European country. In order to improve quality of life in these young children, these data are important and provide insight in potential areas that may benefit from interventions.

The primary aim of this study is to compare health-related quality of life between the general paediatric population and 
children with sickle cell disease. The secondary aim is to analyse whether there is an association in children with sickle cell disease between health-related quality of life and 1) patient's age, 2) disease severity, and 3) caregiver's sociodemographic characteristics.

A retrospective cross-sectional evaluation of TNO-AZL Preschool Children Quality of Life questionnaire (TAPQOL, 0-1 year) and Pediatric Quality of Life Inventory ${ }^{\mathrm{TM}}$ (PedsQL $^{\mathrm{TM}}, 2-7$ years) data was conducted in children aged 0-7 years, living in the Netherlands. Study participants included caregivers of children with sickle cell disease referred for clinical follow-up at the sickle cell comprehensive care centres at Amsterdam UMC and Erasmus MC Rotterdam between April 2012 and October 2020. Clinical data were obtained from medical records record abstraction. Comparisons were made with previously published normative data on health-related quality of life in the general paediatric population, living in the Netherlands.

The study enrolled 136 caregivers of 136 children. On domains where significant differences existed between children with sickle cell disease and the general paediatric population, children with sickle cell disease scored lower with the most extensive impairment in children aged 5-7 years.

Multiple regression models showed a significant negative association between age and health-related quality of life. No association was found between health-related quality of life and disease severity or health-related quality of life and sociodemographic characteristics.

This study has demonstrated that health-related quality of life declines with age in very young children with sickle cell disease, with an extensive impaired health-related quality of life from 5 years of age when compared to the general paediatric population. This underlines the importance of the identification of high-risk patients with significantly impaired healthrelated quality of life as early in life as possible, to apply appropriate interventions for quality of life improvement. Future research should focus on factors influencing healthrelated quality of life in children with sickle cell disease.

\section{SARS-COV-2 INFECTION IN PEDIATRIC ONCOLOGICAL PATIENTS - OUR EXPERIENCE}

Aleksandra Bonevski*, Jasna Leniček Krleža, Jasminka Stepan Giljević, Nuša Matijašić, Maja Pavlović, Nada Rajačić, Filip Jadrijević Cvrlje, Izabela Kranječec, Renata Zrinski Topić. Children's Hospital Zagreb

10.1136/archdischild-2021-europaediatrics.313

The goal of the study was to present patients' demographic characteristics and clinical course of SARS-CoV-2 infection in children with malignancies treated at our Department. Additional goals were to evaluate the impact of infection on the course of diagnosis, treatment and/or follow up of the primary malignant disease and to determine anti-SARS-CoV-2 antibodies by quantitative assay after recovery from infection.

The study's participants were oncological patients, treated and monitored at our Department, who developed SARS-CoV2 infection. Demographic data, symptoms and the impact of infection on diagnosis, treatment and/or follow up of the primary disease were collected from questionnaires, filled by patients' parents, in the presence of a medical doctor. Patients and their parents were informed about the study's concept, and all signed consent forms before data and sample collection took place. Laboratory tests (total proteins, albumins, A, M, G immunoglobulin classes) as well as anti-SARSCoV-2 antibodies were done at Department of Medical Biochemistry of the Children's Hospital Zagreb.

At the time of writing this abstract we have collected complete data on 14 patients, 9 boys. Primary diagnoses were: ALL (5), Wilms tumor (3), Hodgkin's lymphoma (2), rhabdomyosarcoma (2), desmoplastic infantile ganglioglioma (1) and yolk sack tumor (1). Three patients were diagnosed with SARS-CoV-2 infection during intensive treatment, 2 at initial presentation of primary disease, 4 during maintenance treatment, and 5 during follow up. All the participants, except one patient who was initially treated at another hospital and had underwent only rapid antigen test, had positive RT-PCR test. The common most symptom was fever (9), followed by rhinorrhea (5), loss of appetite (4), cough (2), dyspnoea (2), loss of taste/smell (2), sore throat (1), lethargy (1), vomiting (1), diarrhea (1) and abdominal pain (1). None of the patients developed multisystemic inflammatory syndrome. Four patients had asymptomatic infection. Serology test was done 2.5-4.5 months post-infection, and was positive in 10 patients, while 1 patient had values just below the cut off limit $(0.8 \mathrm{U} / \mathrm{mL})$. Out of 9 patients infected during the treatment (initiation, intensive or maintenance treatment), 5 reported short postponement in oncological therapy, and none had delay in crucial diagnostics.

Our study is still ongoing, but according to the results so far, none of our patients developed severe clinical presentation of SARS-CoV-2 infections, and the infection itself did not interfere much with oncological treatment.

Majority of patients developed detectable anti-SARS-CoV-2 antibodies.

\section{VITAMIN D SUPPLY FOR CHILDREN AND ADOLESCENTS WITH CANCER IN THE SOUTH OF RUSSIA}

Svetlana Dolbnya*, Alice Karaseva, Viktoriya Kur'yaninova, Inna Stremenkova, Leonid Klimov. Stavropol State Medical University, Stavropol 355017, Russian Federation

10.1136/archdischild-2021-europaediatrics.314

Study Objective To assess the supply of vitamin D in children and adolescents with cancer in the Stavropol Territory $\left(45^{\circ}\right.$ north latitude).

We examined 36 children with cancer (18 boys and 18 girls). There were 11 children (30.6\%) aged from 0 to 3 years, $16(44.4 \%)$ - from 4 to 10 years, 9 (25.0\%) children from 11 to 18 years. The average age is $7.9 \pm 0.9$ years.

Leukemia was revealed in $19(52.8 \%)$ children, solid tumors - in 9 (25.0\%), lymphomas - in 8 (22.2\%) children.

The median calcidiol level was 17.5 [12.6-23.4] ng/ml. A deficiency of vitamin D (less than $20 \mathrm{ng} / \mathrm{ml}$ ) was detected in $21(58.3 \%)$ children, a deficiency at the level of $20-30 \mathrm{ng} / \mathrm{ml}$ - in $10(27.7 \%)$, a level of more than $30 \mathrm{ng} / \mathrm{ml} \mathrm{-} \mathrm{in} 5(13$, 9\%) of examined children.

Median $25(\mathrm{OH})$ D in children with leukemia was 21.2 [14.6-22.4] ng/ml, with solid tumors - 16.2 [9.3-16.4] ng/ml, with lymphomas - 15.8 [11.7-22.8] ng/ml. Nine (47.4\%) children with leukemia, $7(77.8 \%)$ with solid tumors and 5 $(62.5 \%)$ with lymphomas had a serum calcidiol level of less than $20 \mathrm{ng} / \mathrm{ml}$, deficiency of $20-30 \mathrm{ng} / \mathrm{ml}$ was detected in 6 (31.6\%), $1(11.1 \%)$ and $3(37.5 \%)$ children, respectively, the level of more than $30 \mathrm{ng} / \mathrm{ml}$ was detected in $4(21.0 \%)$ 